\title{
Effects of acute ethanol intoxication in an ovine peritonitis model
}

\author{
Koji Hosokawa, Fuhong Su, Fabio Silvio Taccone, Emiel Hendrik Post, Jacques Creteur and Jean-Louis Vincent ${ }^{*}$ (D)
}

\begin{abstract}
Background: Acute ethanol intoxication has been shown to have contrasting effects on outcomes in sepsis. The aim of this study was to explore the effects of acute ethanol intoxication on hemodynamics, renal function, brain perfusion and lactate/pyruvate in an ovine sepsis model.

Methods: Anesthetized, mechanically ventilated female sheep were randomized to an ethanol group $(n=7)$, which received $1 \mathrm{~g} / \mathrm{kg}$ ethanol diluted in intravenous (i.v.) saline infusion or a control group $(n=7)$, which received the same volume of i.v. saline. Both groups received the treatment for a period of $2 \mathrm{~h}$ prior to induction of sepsis by intraperitoneal injection of feces. Other treatment included fluid resuscitation but no vasopressors or antibiotics. Global hemodynamics, renal blood flow, brain cortex laser Doppler flowmetry and microdialysis analyses were recorded hourly.

Results: In the ethanol group, blood ethanol concentrations were $137 \pm 29 \mathrm{mg} / \mathrm{dL}$ at the time of feces injection and decreased to become undetectable by $12 \mathrm{~h}$. Arterial hypotension occurred earlier in the ethanol than in the control group (8 [7-12] vs. 14 [11-20] hours, $p=0.03$ ). Lactate levels increased to $>2 \mathrm{mmol} / \mathrm{L}$ earlier in the ethanol group. Renal dysfunction (9 [6-13] vs. 13 [12-15] hours, $p=0.05$ ) and oliguria (urine output $<0.5 \mathrm{~mL} / \mathrm{kg} / \mathrm{h} ; 10$ [7-12] vs. $13[12,13]$ hours, $p=0.01$ ) developed earlier in the ethanol than in the control group. Brain blood flow and lactate/pyruvate were unaffected. There was no significant difference in survival time.

Conclusions: Acute ethanol intoxication in this model of peritonitis resulted in earlier development of shock and renal dysfunction but did not alter brain perfusion and metabolism or short-term survival.
\end{abstract}

Keywords: Ethanol intoxication, Sepsis, Septic shock, Renal blood flow, Brain perfusion, Lactate/pyruvate

\section{Background}

Sepsis and septic shock remain a major concern with high associated morbidity and mortality [1-4]. Chronic ethanol abuse is known to be associated with worse outcomes from sepsis [5-7], but the impact of acute ethanol intoxication is controversial. In animal studies, despite consistent reports of increased mortality, blood pressure increased in one murine endotoxemia model exposed to acute ethanol loading (100 $\mathrm{mg} / \mathrm{kg} / \mathrm{h}$ for $2 \mathrm{~h}$ by intravenous infusion) [8] but decreased in a rat endotoxemia model (intra-peritoneal ethanol injection of $2.2-5.5 \mathrm{~g} / \mathrm{kg}$ ) [9]. No specific cardiovascular effects were observed in studies using a pig endotoxemia model with ethanol loading $(3 \mathrm{~g} / \mathrm{kg}$ by gastric lavage) [10]. In an observational study including 11,850

\footnotetext{
* Correspondence: jlvincent@intensive.org

Department of Intensive Care, Erasme University Hospital, Université Libre de Bruxelles, Brussels, Belgium
}

adult patients [11], a detectable blood ethanol concentration at hospitalization was associated with decreased odds of 30-day mortality and a blood ethanol concentration > $160 \mathrm{mg} / \mathrm{dL}$ was associated with significantly decreased odds of developing sepsis and bloodstream infection. In another observational study including 31,364 emergency patients with acute ethanol intoxication, the presence of sepsis symptoms, such as tachycardia, hypotension, hypothermia, fever and hypoxia, was associated with increased odds of critical illness [12]. Acute ethanol intoxication has also been reported to be independently associated with an increase in sepsis complications in patients with traumatic brain injury (TBI) [13, 14]. In 23,983 patients with TBI, pneumonia and urinary tract infections were more common in patients with acute ethanol intoxication than in those without [15]. Similar findings were reported in patients with traumatic spinal cord injury [16].

(c) The Author(s). 2018 Open Access This article is distributed under the terms of the Creative Commons Attribution 4.0 International License (http://creativecommons.org/licenses/by/4.0/), which permits unrestricted use, distribution, and 
Lower systemic interleukin (IL)-6 levels and leukocyte counts have been reported in TBI patients with acute ethanol intoxication [17], suggesting an immunosuppressive effect of ethanol, although in this study there were no significant differences in occurrence of sepsis or pneumonia in patients with positive or negative ethanol tests.

There are no specific data regarding the effects of acute ethanol intoxication on the occurrence of specific organ dysfunctions in patients with sepsis. Thus, we tested the hypothesis that acute ethanol intoxication may have deleterious hemodynamic effects that could affect kidney and brain perfusion and brain lactate/ pyruvate ratio in a large sheep model of fecal peritonitis.

\section{Methods}

The local animal ethics committee at the Université Libre de Bruxelles approved the present study (381 N) and we followed the EU Directive 2010/63/EU for animal experiments and the ARRIVE guidelines for animal research.

Female Ovis aries sheep (aged 6-9 months) were obtained from a local farm (BE 400108-48). The sheep were allowed to adapt to the animal facility for 1 week prior to the study and were then fasted overnight. We chose to use sheep of just one sex to reduce heterogeneity and selected female sheep because bladder catheterization is easier. On the day of the study, sheep were randomized to an ethanol group $(n=7)$ that received a $1 \mathrm{~g} / \mathrm{kg}$ infusion of ethanol (Ethanol $96^{\circ}$ Sterop, $96 \%$, diluted to $20 \%$ in $\mathrm{NaCl} 0.9 \%$ ) and a control group $(n=7)$ that received the same volume of saline. The ethanol/control infusion was continued throughout the surgical preparation until sepsis induction (about $2 \mathrm{~h}$ ). The dose of ethanol and the duration of administration were chosen to achieve a target concentration of blood ethanol of $100-150 \mathrm{mg} / \mathrm{dL}$ to limit any major metabolic and hemodynamic changes during infusion and to achieve elimination of blood ethanol within 10-12 h. This level was chosen based first on results from a retrospective study by Stehman et al. in critically ill patients showing that a detectable blood ethanol level $>80 \mathrm{mg} / \mathrm{dL}$ at hospitalization was associated with significantly decreased odds of 30-day mortality [11]. And second, in a pilot study in our animals, high doses of alcohol $(2 \mathrm{~g} / \mathrm{kg})$ induced hemolysis and rapid death.

\section{Surgical preparation}

Animal preparation and surgical procedures were the same as previously reported [18]. Briefly, the animals were premedicated with i.m. midazolam $(0.25 \mathrm{mg} / \mathrm{kg}$, Dormicum; Roche SA, Brussels, Belgium) and ketamine hydrochloride $(20 \mathrm{mg} / \mathrm{kg}$, Imalgine; Merial, Lyon, France). We then placed a peripheral venous line (14G, Surflo IV Catheter, Terumo Medical Company, Belgium) in the cephalic vein and inserted an oral endotracheal tube (I.D. $8 \mathrm{~mm}$, Hi-Contour, Mallinckrodt Medical, Athlone, Ireland). Mechanical ventilation was provided (Servo 300 ventilator, Siemens-Elema, Solna, Sweden) using a tidal volume of $10 \mathrm{~mL} / \mathrm{kg}$, a respiratory rate of 15-25/min, a $\mathrm{F}_{\mathrm{I}} \mathrm{O}_{2}$ of $0.25-0.80$ titrated to keep $\mathrm{PaCO}_{2}$ between 35 and $45 \mathrm{mmHg}$ and a positive end-expiratory pressure (PEEP) of $5 \mathrm{cmH}_{2} \mathrm{O}$. A heat-moisture exchanger (HMEF 750/S GE Healthcare, Helsinki, Finland) was used. The animals were anesthetized with midazolam $(0.6-3.0 \mathrm{mg} / \mathrm{kg} / \mathrm{h})$, ketamine hydrochloride $(8-40 \mathrm{mg} / \mathrm{kg} / \mathrm{h})$ and morphine $(0.4-2.0 \mathrm{mg} / \mathrm{kg} / \mathrm{h})$ throughout the experiment. A neuromuscular blocker was also given (rocuronium, $10 \mu \mathrm{g} / \mathrm{kg} / \mathrm{h}$ ).

Under sterile conditions, we inserted an arterial catheter (Leader-Cath, 4.5 Fr, Vygon, Ecouen, France) in the right carotid artery and an introducer (Intro-Flex, 8.5 Fr, Edwards Lifesciences, Irvine, CA) in the right jugular vein for a $7 \mathrm{Fr}$ pulmonary artery catheter (Swan-Ganz catheter, Edwards Lifesciences). Feces were collected via surgical perforation of the cecum. The cecum was then closed and a plastic tube (Beldico, Aye, Belgium) placed in the abdominal cavity for later introduction of feces. A flow probe (4PS, Transonic Systems, Ithaca, NY) was placed around the left renal artery through a lateral oblique incision. Two holes were drilled in the skull $(1.2 \mathrm{~mm}$, within $1 \mathrm{~cm}$ from the ear line at $1 \mathrm{~cm}$ lateral of midline) (Guangzhou Hekang Medical Instrument, Guangzhou, China) to insert a laser Doppler flowmetry probe (Oxyflo, Single Fiber Driver Probe, Optronix, London, England) and a microdialysis membrane catheter (CMA 20 Microdialysis Probe, CMA, Solna, Sweden).

\section{Sepsis induction and management}

Baseline measurements of all variables were taken and autologous feces $(1.5 \mathrm{~g} / \mathrm{kg})$ were then introduced into the abdominal cavity to induce severe peritonitis.

Fluid resuscitation consisting of $4-20 \mathrm{~mL} / \mathrm{kg} / \mathrm{h}$ of Ringer's lactate solution (Hartmann, Baxter) and 6\% hydroxyethyl starch (Voluven, Fresenius Kabi, Bad Homburg, Germany) in a 1:1 ratio was given to keep pulmonary artery balloon-occluded pressure at the baseline level. No vasopressors were given. Sedatives and analgesics $(0.6 \mathrm{mg} / \mathrm{kg} / \mathrm{h}$ midazolam, $8 \mathrm{mg} / \mathrm{kg} / \mathrm{h}$ ketamine and $0.4 \mathrm{mg} / \mathrm{kg} / \mathrm{h}$ morphine) were administered continuously. Hypoglycemia (blood glucose $<50 \mathrm{mg} / \mathrm{dL}$ ) and hypokalemia (defined as potassium $<3.5 \mathrm{mmol} / \mathrm{L}$ ) were corrected. Metabolic acidosis was defined as $\mathrm{pH}$ $<7.35$ with bicarbonate $<24 \mathrm{mmol} / \mathrm{L}$. Hyperchloremia was defined as a chloride concentration exceeding $107 \mathrm{mmol} / \mathrm{L}$. Renal dysfunction was defined as a decrease in renal blood flow to $<75 \%$ of baseline and a urine output $<0.5 \mathrm{~mL} / \mathrm{kg}$. 


\section{Measurements}

Observations were continued until spontaneous death. MAP, mean pulmonary arterial pressure (MPAP) (displayed on a SC9000, Siemens, Munich, Germany), blood temperature and cardiac output (measured on Vigilance, Edwards Lifesciences, Irvine, CA) were recorded hourly. For cardiac output measurement, continuous cardiac output was measured automatically when core body temperature was $<41{ }^{\circ} \mathrm{C}$, and using a bolus infusion (10 $\mathrm{mL} 4{ }^{\circ} \mathrm{C}$ of $0.9 \%$ saline) when the blood temperature increased $>41{ }^{\circ} \mathrm{C}$. Derived variables were calculated using standard formulas. Arterial blood gas and lactate concentrations (Cobas b 123, Roche, Rotkreuz, Switzerland) were measured hourly. Every $4 \mathrm{~h}$, citrated serum was separated by centrifugation (3000 rpm, $6 \mathrm{~min}$ ) and stored at $-20{ }^{\circ} \mathrm{C}$ to measure coagulation variables in the biochemical laboratory of Erasme Hospital. Absolute values of renal blood flow (TS420, Transonic Systems) and laser Doppler flowmetry for brain regional microcirculation (Oxford Optronix OxyFlow 2000) were recorded hourly and normalized to baseline values. For microdialysis analysis, an artificial solution (Perfusion fluid CNS, CMA Microdialysis AB) was continually perfused at the rate of $0.3 \mu \mathrm{g} / \mathrm{min}$ (CMA402 Syringe Pump, CMA Microdialysis AB). One-hour effluent samples were immediately analyzed for glucose, lactate and pyruvate concentrations (ISCUS flex Microdialysis Analyzer, CMA Microdialysis AB). A microdialysis lactate/ pyruvate ratio $>25$ was used to define tissue ischemia in the brain cortex [19].

\section{Statistical analysis}

In this exploratory trial, we did not perform an a priori calculation of the sample size, but selected the number of animals based on our previous experience with this animal model [18, 19]. Statistical analysis was performed using JMP $^{\circledR}$ (Ver. 10. SAS Institute, Cary, NC). Continuous variables are presented as means \pm standard deviation $(\mathrm{SD})$ or median $[25,75 \%$ interquartile range (IQR)].

To estimate the influence of ethanol administration over the observational period, a mixed-effects polynomial regression model with restricted maximum likelihood (REML) estimation was used to examine the mean differences in time-series variables between the groups. The effects of time and group, as well as the interaction between group and time, were tested as fixed effects and subjects were introduced as random effects. If there were significant differences, a Student's t-test (two-tailed) was used for comparison of the mean of these variables at each point between the two groups. Time to develop several predefined organ failure parameters and survival time between groups was tested using a log-rank test. A $p$ value of $<0.05$ was considered statistically significant.

\section{Results}

The ethanol and control groups had similar characteristics at the start of ethanol administration and at the moment of feces injection (Table 1 and in Additional file 1: Table S1). In the ethanol group, the ethanol concentration in blood was largest at the time of feces injection $(137 \pm 29 \mathrm{mg} / \mathrm{dL})$ and ethanol was no longer detectable at $12 \mathrm{~h}$ (Additional file 1: Figure S1).

\section{General course}

The two groups had similar cardiac filling pressures, fluid balance and cardiac index throughout the study period (Table 1 and Additional file 1: Table S2). MAP reached $<65 \mathrm{mmHg}$ earlier in the ethanol group (Table 2).

Metabolic acidosis developed earlier in the ethanol than in the control group (Tables 1 and 2, Fig. 1), and was associated with a much earlier increase in arterial lactate concentrations in the ethanol group (from $1 \mathrm{~h}$ after feces injection) than in the control group (from $12 \mathrm{~h}$ after feces injection) (Table 1). The anion gap (Additional file 1: Table S2) and arterial sodium concentration (Fig. 1) decreased less in the ethanol group than in the control group. Hyperchloremia developed in both groups (Fig. 1).

\section{Renal function}

Renal blood flow decreased to $<75 \%$ of baseline (9 [6-13] vs $13[12-15] \mathrm{h}, p=0.05)$ and urinary output to $<0.5 \mathrm{~mL} / \mathrm{kg}$ (10 [7-12] vs 13 [12-13] h, $p=0.01$ ) earlier in the ethanol than in the control group (Table 2).

\section{Brain regional perfusion and lactate/pyruvate}

Brain perfusion assessed by laser Doppler flowmetry was similar in the two groups throughout the study (Table 1). Brain microdialysis analysis showed that interstitial glucose decreased and lactate increased in both groups. Interstitial pyruvate increased initially in both groups and then decreased from about $12 \mathrm{~h}$; as a result, the lactate/pyruvate ratio started to increase at the end of the observation period. All these changes were similar in the two groups (Table 1).

\section{Survival time}

The survival time was shorter in the ethanol group than in the control group (16 vs. $20 \mathrm{~h}$ ), but the differences were not statistically significant $(p=0.11)$ (Table 2$)$.

\section{Discussion}

In this ovine sepsis model, we showed that acute ethanol intoxication induced earlier development of hypotension and lactic acidosis, and earlier decrease in bicarbonate and $\mathrm{pH}$. There was also an earlier decrease in renal blood flow and urine output in the animals who received 
Table 1 Evolution of measured variables in the two groups (ethanol, $n=7$ vs. control, $n=7$ )

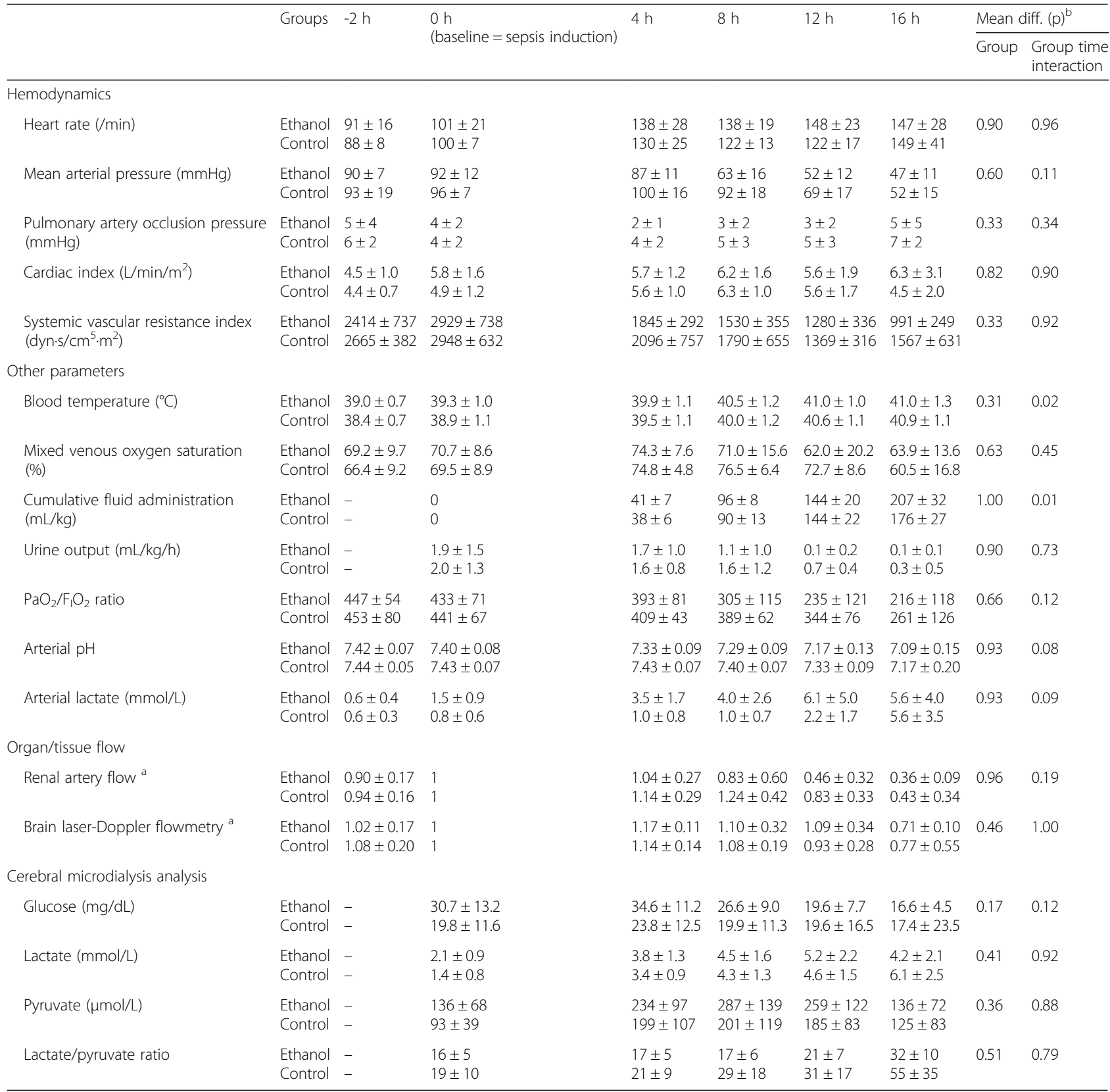

Values are presented as mean $\pm \mathrm{SD} .{ }^{\mathrm{a}}$, relative flow with baseline flow defined as $1 .{ }^{\mathrm{b}}$, mixed model

ethanol; however, ethanol did not affect brain cortex perfusion or lactate/pyruvate.

Acute ethanol intoxication induced earlier hypotension despite adequate fluid resuscitation in the two groups. This effect may be explained by ethanol-induced upregulation of inducible nitric oxide synthase (iNOS). In a rat endotoxemia model, ethanol increased myocardial and aortic NOS, aggravating hypotension and decreasing cardiac output $[20,21]$. Conversely, also in rats, Ajisaka et al. [8] using low dose ethanol $(100 \mathrm{mg} / \mathrm{kg} / \mathrm{h}$ for $2 \mathrm{~h})$ and Greenberg et al. [9] using high dose ethanol
$(2.2-5.5 \mathrm{~g} / \mathrm{kg}$, intraperitoneally) both showed attenuation of endotoxin-induced hypotension, suggesting ethanol-induced suppression of endothelial NOS expression. In addition to obvious differences, such as different species and sepsis models, another possible reason for the conflicting results may be related to management of fluid status: for example the rat endotoxemia model used by Greenberg et al. [9] had inadequate fluid resuscitation and hemodynamic monitoring, which could potentially weaken the interpretation of their results. Furthermore, oxidative stress and autonomic 
Table 2 Time to develop predefined major abnormalities

\begin{tabular}{llll}
\hline & Ethanol, $n=7$ & Control, $n=7$ & $\mathrm{p}$ (Log-rank) \\
\hline $\mathrm{MAP}<65 \mathrm{mmHg}$ & $8[7-12]$ & $14[11-20]$ & 0.03 \\
$\mathrm{SVRI}<1200 \mathrm{dyn} \cdot \mathrm{s} / \mathrm{cm}^{5} \cdot \mathrm{m}^{2}$ & $11[9-13]$ & $14[10-16]$ & 0.19 \\
Renal blood flow $<\times 0.75^{\mathrm{a}}$ & $9[6-13]$ & $13[12-15]$ & 0.05 \\
Hourly $\mathrm{UO}<0.5 \mathrm{~mL} / \mathrm{kg}$ & $10[7-12]$ & $13[12-13]$ & 0.01 \\
$\mathrm{pH}<7.25$ & $8[4-15]$ & $15[13-20]$ & 0.05 \\
$\mathrm{BT}$ increase $>+1.5^{\circ} \mathrm{C}^{\mathrm{a}}$ & $10[8-16]$ & $11[7-12]$ & 0.54 \\
$\mathrm{PaO}_{2} / \mathrm{F}_{1} \mathrm{O}_{2}$ ratio $<200$ & $13[11-15]$ & $17[13-20]$ & 0.13 \\
Brain LD $<\times 0.8^{\mathrm{a}}$ & $16[13-16]$ & $16[13-19]$ & 0.49 \\
Brain MD LPR $>25$ & $14[10-16]$ & $12[8-14]$ & 0.59 \\
Death & $16[14-22]$ & $20[19-24]$ & 0.11
\end{tabular}

All data (hours) are presented as median [IQR]. ${ }^{\text {a }}$, compared with baseline (defined as the time of feces injection) values

$B T$ blood temperature, $L D$ laser Doppler, $L P R$ lactate pyruvate ratio, MAP mean arterial pressure, $M D$ microdialysis, SVRI systemic vascular resistance index, $U O$ urine output

dysregulation were shown to be responsible for the hypotension observed in a rat model of acute ethanol exposure (1 g/kg, intragastric) [22]. Impaired release of arginine vasopressin, which may be the result of augmented central NO inhibition, may also play a role [23]. These possible mechanisms need to be confirmed in future studies.
In addition to earlier hypotension, acutely intoxicated animals also showed an earlier onset of lactic acidosis. In a rat blunt (thoracic) chest trauma and hemorrhagic shock model, Wagner et al. showed that acute ethanol intoxication induced both respiratory and metabolic acidosis [24]. In guinea pigs with hemorrhagic shock, acute ethanol intoxication also exacerbated lactic acidosis $[25,26]$. Zehtabchi et al. reported a higher prevalence of lactic acidosis in ethanol-intoxicated patients than in other patients in the emergency department [27]. Respiratory acidosis is related to depression in respiratory rate [28], whereas metabolic acidosis may be related to alcoholic ketoacidosis associated with an increased anion gap [29] and renal dysfunction [24], both of which were observed in our study. Because we used mechanical ventilation to keep $\mathrm{PaCO}_{2}$ within normal ranges, we cannot exclude the possibility that respiratory acidosis may have occurred in our model.

Acute ethanol intoxication resulted in the earlier development of renal dysfunction, suggested by an earlier decrease in renal blood flow and urine output. This was likely due to the earlier decrease in arterial pressure. However, brain cortex perfusion and metabolism and mortality were not affected, possibly because kidney autoregulation may not be as effective as cerebral
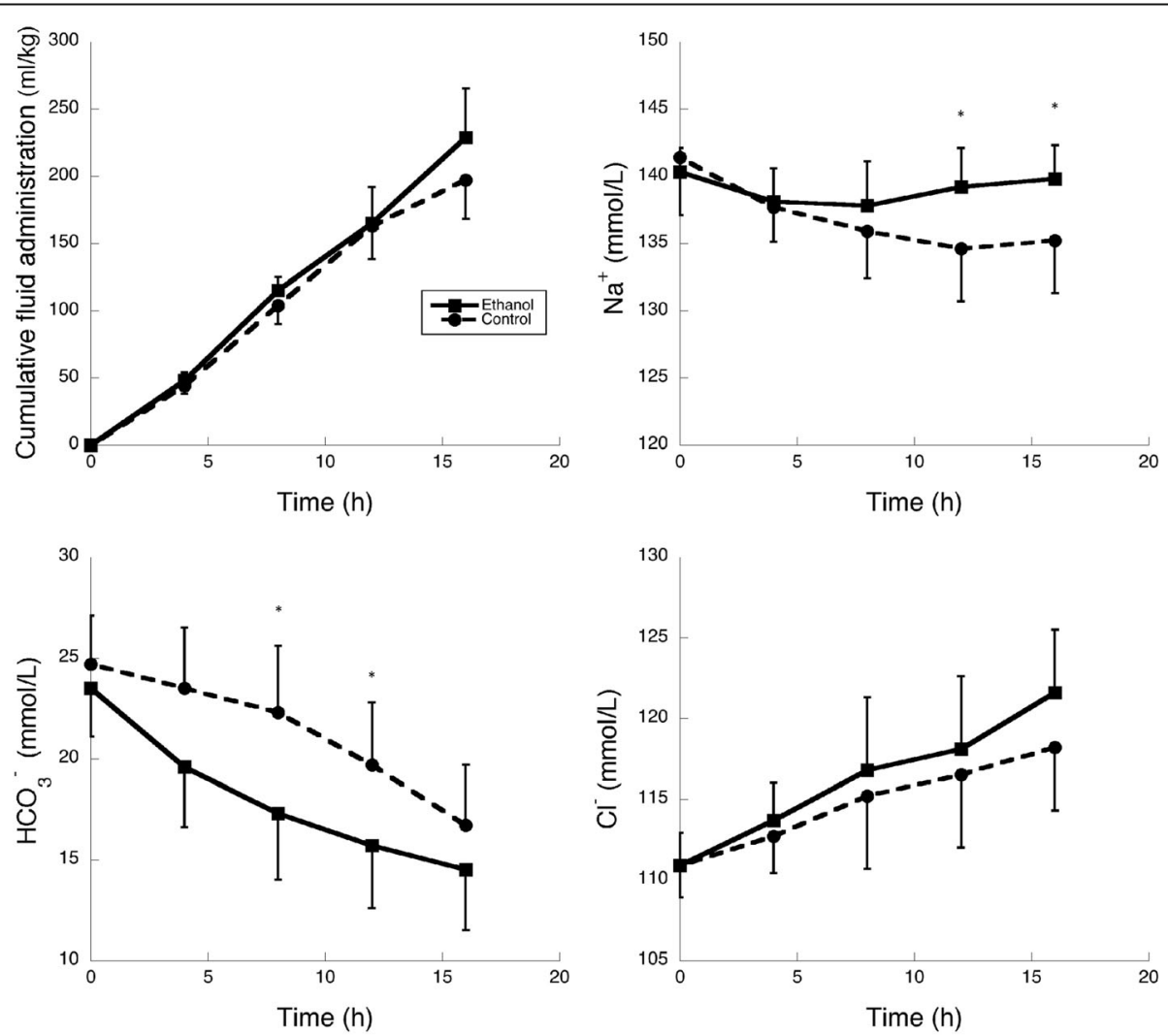

Fig. 1 Cumulative fluid administration, arterial sodium, bicarbonate and chloride concentrations in the two groups. ${ }^{*}$ difference between groups at the $p<0.05$ level 
autoregulation. Other possible explanations could be that the microcirculation in the brain was impaired less than that in the kidney. Finally, we cannot exclude the possibility that the brain may be able to use ethanol metabolites, such as ketone, more efficiently than the kidney.

The shorter survival time in the ethanol-intoxicated animals did not reach statistical significance possibly because the number of animals was too small, but we did not believe it was justified to add animals for this reason, especially since this observation is compatible with other reports. Woodman et al. showed that endotoxin shortened survival in ethanol intoxicated pigs [10]. Nishida et al. reported that acute ethanol administration increased 24-h lethality in a mouse sepsis model from 40 to $92 \%$ [30]. Possible mechanisms to explain the shortened survival could be related to the effects of acute ethanol exposure on innate and adaptive immunity [31-33] and oxidative stress [34, 35]. However, in a series of 11,850 medical and surgical ICU patients, Stehman et al. [11] reported that patients with acute ethanol intoxication had a lower risk of blood stream infection, sepsis and organ dysfunction, and death than the other patients, raising potential questions regarding the translation of these animal results to the clinical setting.

Ethanol metabolism is similar in sheep and humans [36]. Nevertheless, our study has several limitations. First, the extent of ethanol-induced immune changes may depend on the route of administration, the amount and duration of ethanol consumed, and the strain and sex of animal species used [37]. Second, oral intake of ethanol may also induce gut mucosal injury, which could further harm the host. Furthermore, depending on the administration route (oral, intra-peritoneal or intra-venous), different doses (from $10 \mathrm{mg} / \mathrm{kg}$ to $6 \mathrm{~g} / \mathrm{kg}$ ) have been used in acute ethanol intoxication models. We chose to give only one dose $(1 \mathrm{~g} / \mathrm{kg})$ over two hours rather than multiple doses, which may limit interpretation of our results given the relatively mild level of ethanol intoxication. Third, in our anesthetized sheep model, we do not give antibiotics or surgical treatment for peritonitis in order to achieve a uniformly lethal outcome. Hence, we could not study the long-term effects of ethanol intoxication. Moreover, the use of previously healthy sheep may not translate readily to the complex ICU patient with comorbidities. Fourth, HES solutions have been associated with potential harmful renal effects in clinical studies [38]; however, some colloid is necessary in this model to limit edema formation and we are unable to given human albumin. Nevertheless, the amounts of HES administered were small and given over a short time period so we do not believe they will have had a major impact on renal function in this model.
Finally, we cannot address all the possible mechanisms involved because we did not measure ethanol metabolites or mediators, including inflammatory factors.

\section{Conclusion}

In a clinically relevant ovine model of sepsis, acute ethanol intoxication resulted in earlier development of shock, and was associated with reduced renal blood flow and urine output, but did not alter brain perfusion or metabolism.

\section{Additional file}

Additional file 1: Supplementary Content including: Table S1. Animals at baseline. Figure S1 Blood ethanol concentrations over time. Table S2. Evolution of other measured variables in the two groups. (DOCX $45 \mathrm{~kb})$

Abbreviations

iNOS: Inducible nitric oxide synthase; MAP: Mean arterial pressure; MPAP: Mean pulmonary artery pressure

\section{Acknowledgements}

Laboratory and animal welfare issues were organized by Dr. Catherine Vroonen. Blood ethanol and coagulation tests were conducted by Drs. Béatrice Gulbis and Ingrid Beukinga.

\section{Availability of data and materials}

The datasets used and/or analyzed during the current study are available from the corresponding author on reasonable request.

\section{Authors' contributions}

$\mathrm{KH}, \mathrm{FS}$, JLV designed the study; KH, FS, EHP performed the experiments and collected the data; KH, FS and JLV analyzed the data; FS, KH wrote the manuscript; KH, FST, EHP, JC, JLV revised the manuscript for critical content; all authors read and approved the final text

\section{Ethics approval}

The local animal ethics committee at the Université Libre de Bruxelles approved the present study (381 N) and we followed the EU Directive 2010/63/EU for animal experiments and the ARRIVE guidelines for animal research.

\section{Competing interests}

The authors declare that they have no competing interests.

\section{Publisher's Note}

Springer Nature remains neutral with regard to jurisdictional claims in published maps and institutional affiliations.

Received: 19 February 2018 Accepted: 30 May 2018

Published online: 19 June 2018

\section{References}

1. Yebenes JC, Ruiz-Rodriguez JC, Ferrer R, Cleries M, Bosch A, Lorencio C, et al. Epidemiology of sepsis in Catalonia: analysis of incidence and outcomes in a European setting. Ann Intensive Care. 2017;7:19.

2. Kaukonen KM, Bailey M, Suzuki S, Pilcher D, Bellomo R. Mortality related to severe sepsis and septic shock among critically ill patients in Australia and New Zealand, 2000-2012. JAMA. 2014:311:1308-16.

3. Vincent JL, Marshall JC, Namendys-Silva SA, Francois B, Martin-Loeches I, Lipman J, et al. Assessment of the worldwide burden of critical illness: the intensive care over nations (ICON) audit. Lancet Respir Med. 2014;2:380-6.

4. Sakr Y, Elia C, Mascia L, Barberis B, Cardellino S, Livigni S, et al. Epidemiology and outcome of sepsis syndromes in Italian ICUs: a muticentre, 
observational cohort study in the region of piedmont. Minerva Anestesiol. 2013;79:993-1002.

5. O'Brien JM Jr, Lu B, Ali NA, Martin GS, Aberegg SK, Marsh CB, et al. Alcohol dependence is independently associated with sepsis, septic shock, and hospital mortality among adult intensive care unit patients. Crit Care Med. 2007:35:345-50.

6. Moss M, Parsons PE, Steinberg KP, Hudson LD, Guidot DM, Burnham EL, et al. Chronic alcohol abuse is associated with an increased incidence of acute respiratory distress syndrome and severity of multiple organ dysfunction in patients with septic shock. Crit Care Med. 2003;31:869-77.

7. Bhatty M, Pruett SB, Swiatlo E, Nanduri B. Alcohol abuse and Streptococcus pneumoniae infections: consideration of virulence factors and impaired immune responses. Alcohol. 2011;45:523-39.

8. Ajisaka H, Okajima M, Goto Y, Taniguchi T, Inaba H. Effects of acute lowdose ethanol on inflammatory reactions to endotoxin-induced shock in rats. J Toxicol Sci. 2012;37:649-54.

9. Greenberg SS, Xie J, Powers DR, Giles TD. Ethanol suppresses endotoxin but not platelet activating factor-induced hypotension and nitric oxide. Alcohol Clin Exp Res. 1996;20:1260-8.

10. Woodman GE, Fabian TC, Beard JD, Proctor KG. Actions of acute ethanol intoxication on cardiopulmonary function after an endotoxin challenge. Surgery. 1996;120:80-92.

11. Stehman CR, Moromizato T, McKane CK, Mogensen KM, Gibbons FK Christopher KB. Association between blood alcohol concentration and mortality in critical illness. J Crit Care. 2015;30:1382-9.

12. Klein LR, Cole JB, Driver BE, Battista C, Jelinek R, Martel ML. Unsuspected critical illness among emergency department patients presenting for acute alcohol intoxication. Ann Emerg Med. 2018;71:279-88.

13. Salim A, Teixeira P, Ley EJ, DuBose J, Inaba K, Margulies DR. Serum ethanol levels: predictor of survival after severe traumatic brain injury. J Trauma. 2009;67:697-703.

14. Plurad D, Demetriades D, Gruzinski G, Preston C, Chan L, Gaspard D, et al. Motor vehicle crashes: the association of alcohol consumption with the type and severity of injuries and outcomes. J Emerg Med. 2010;38:12-7.

15. Pandit V, Patel N, Rhee P, Kulvatunyou N, Aziz H, Green DJ, et al. Effect of alcohol in traumatic brain injury: is it really protective? J Surg Res. 2014;190:634-9.

16. Crutcher CL, Ugiliweneza B, Hodes JE, Kong M, Boakye M. Alcohol intoxication and its effects on traumatic spinal cord injury outcomes. J Neurotrauma. 2014:31:798-802.

17. Wagner N, Akbarpour A, Mors K, Voth M, Stormann P, Auner B, et al. Alcohol intoxication reduces systemic interleukin-6 levels and leukocyte counts after severe TBI compared with not intoxicated TBI patients. Shock. 2016;46: 261-9.

18. Su F, Brands R, Wang Z, Verdant C, Bruhn A, Cai Y, et al. Beneficial effects of alkaline phosphatase in septic shock. Crit Care Med. 2006;34:2182-7.

19. Taccone FS, Su F, De DC, Abdellhai A, Pierrakos C, He X, et al. Sepsis is associated with altered cerebral microcirculation and tissue hypoxia in experimental peritonitis. Crit Care Med. 2014;42:e114-e122.

20. El-Mas MM, Fan M, Abdel-Rahman AA. Endotoxemia-mediated induction of cardiac inducible nitric-oxide synthase expression accounts for the hypotensive effect of ethanol in female rats. J Pharmacol Exp Ther. 2008; 324:368-75.

21. El-Mas MM, Zhang J, Abdel-Rahman AA. Upregulation of vascular inducible nitric oxide synthase mediates the hypotensive effect of ethanol in conscious female rats. J Appl Physiol (1985 ). 2006;100:1011-8.

22. Ibrahim BM, Fan M, Abdel-Rahman AA. Oxidative stress and autonomic dysregulation contribute to the acute time-dependent myocardial depressant effect of ethanol in conscious female rats. Alcohol Clin Exp Res. 2014;38:1205-15.

23. Whitaker AM, Molina PE. Angiotensin (1-7) contributes to nitric oxide tonic inhibition of vasopressin release during hemorrhagic shock in acute ethanol intoxicated rodents. Life Sci. 2013;93:623-9.

24. Wagner N, Franz N, Dieteren S, Perl M, Mors K, Marzi I, et al. Acute alcohol binge deteriorates metabolic and respiratory compensation capability after blunt chest trauma followed by hemorrhagic shock-a new research model. Alcohol Clin Exp Res. 2017:41:1559-67.

25. McDonough KH, Giaimo ME, Miller HI, Gentilello LM. Low-dose ethanol alters the cardiovascular, metabolic, and respiratory compensation for severe blood loss. J Trauma. 2002:53:541-8.
26. McDonough KH, Swafford AN Jr, Giaimo ME, Adamson TW, Miller HI. Mode of ethanol administration influences the severity of hemorrhage-induced lactic acidemia in conscious Guinea pigs. J Cardiovasc Pharmacol. 2010;56: 234-40.

27. Zehtabchi S, Sinert R, Baron BJ, Paladino L, Yadav K. Does ethanol explain the acidosis commonly seen in ethanol-intoxicated patients? Clin Toxicol (Phila). 2005;43:161-6.

28. Sahn SA, Lakshminarayan S, Pierson DJ, Weil JV. Effect of ethanol on the ventilatory responses to oxygen and carbon dioxide in man. Clin Sci Mol Med. 1975;49:33-8.

29. Hojer J. Severe metabolic acidosis in the alcoholic: differential diagnosis and management. Hum Exp Toxicol. 1996;15:482-8.

30. Nishida J, Ekataksin W, McDonnell D, Urbaschek R, Urbaschek B, McCuskey RS. Ethanol exacerbates hepatic microvascular dysfunction, endotoxemia, and lethality in septic mice. Shock. 1994;1:413-8.

31. Szabo G, Mandrekar P. A recent perspective on alcohol, immunity, and host defense. Alcohol Clin Exp Res. 2009:33:220-32.

32. Szabo G, Dolganiuc A, Dai Q, Pruett SB. TLR4, ethanol, and lipid rafts: a new mechanism of ethanol action with implications for other receptor-mediated effects. J Immunol. 2007;178:1243-9.

33. Goral J, Karavitis J, Kovacs EJ. Exposure-dependent effects of ethanol on the innate immune system. Alcohol. 2008:42:237-47.

34. Jung MK, Callaci JJ, Lauing KL, Otis JS, Radek KA, Jones MK, et al. Alcohol exposure and mechanisms of tissue injury and repair. Alcohol Clin Exp Res. 2011;35:392-9.

35. Cederbaum Al, Lu Y, Wu D. Role of oxidative stress in alcohol-induced liver injury. Arch Toxicol. 2009;83:519-48.

36. Jean-Blain C, Durix A, Tranchant B. Kinetics of ethanol metabolism in sheep. Reprod Nutr Dev. 1992;32:83-90.

37. Spitzer JA. Gender differences in some host defense mechanisms. Lupus. 1999;8:380-3.

38. Perner A, Haase N, Guttormsen AB, Tenhunen J, Klemenzson G, Aneman A, et al. Hydroxyethyl starch 130/0.4 versus Ringer's acetate in severe sepsis. N Engl J Med. 2012;367:124-34.

\section{Ready to submit your research? Choose BMC and benefit from:}

- fast, convenient online submission

- thorough peer review by experienced researchers in your field

- rapid publication on acceptance

- support for research data, including large and complex data types

- gold Open Access which fosters wider collaboration and increased citations

- maximum visibility for your research: over $100 \mathrm{M}$ website views per year

At BMC, research is always in progress.

Learn more biomedcentral.com/submissions 